\title{
Editor's Introduction: The Robert H. Wood Special Issue
}

\author{
Joseph A. Rard ${ }^{1}$
}

Published online: 1 May 2015

(C) Springer Science+Business Media New York 2015

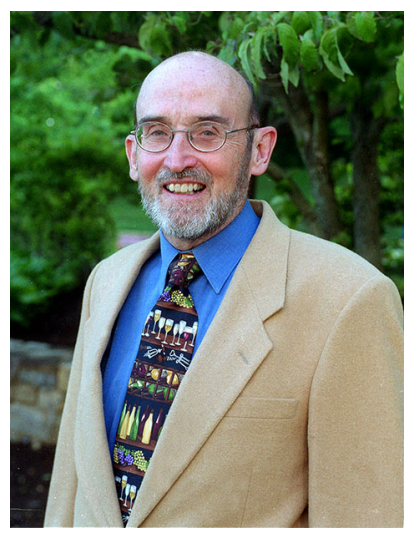

Professor Robert H. Wood (this picture was supplied by Professor Gregory H. Zimmerman)

Professor Robert H. Wood is well known to many of the readers of this special issue of the Journal of Solution Chemistry because of his considerable contributions to the field of solution chemistry spanning many years, especially in the area of calorimetry and also electrolytic conductivity and equations of state. This special issue is based on a symposium held at the 67th (North American) Calorimetry Conference (CALCON2013) held in Atlantic City, New Jersey, August 18-22, 2013: Aqueous Solutions, Fluid Mixtures and Polymers-A Tribute to Robert H. Wood on the occasion of his 80th Birthday. This symposium was organized by and chaired by Professor Emmerich Wilhelm and Professor

Joseph A. Rard

solution_chemistry2@comcast.net

14363 Claremont Way, Livermore, CA, USA 
Jean-Pierre E. Grolier. All but one of the papers in this issue are based on lectures presented at that symposium, while the remaining one is a contributed paper. The editors of this journal are pleased to publish this well-deserved special issue.

Early on Bob Wood recognized the great potential of flow densimetry and flow calorimetry for measuring densities/molar volumes and heat capacities, and together with his students, postdocs and colleagues, developed the equipment and experimental techniques that greatly extended the experimental range to very high temperatures and high pressures extending even into the supercritical region; both electrolyte and non-electrolyte solutions were investigated. Prior to this work, there was a scarcity of data for these properties because of the considerable difficulties in working with such solutions, which become corrosive under these extreme conditions. Subsequent work in his laboratory extended these techniques to the measurement of electric conductivities of aqueous electrolytes at high temperatures and high pressures, another area with very little prior experimental data. These experimental results gave rise to much new insight into the behavior of fluid mixtures over wide ranges of temperature and pressure.

The tribute by Emmerich Wilhelm in this issue, "In Appreciation of Professor Robert H. Wood", summarizes some of this important work from Bob Woods' laboratory published since the 1980s. In the 1960s and 1970s, Bob and his research team published high quality enthalpy data for many inorganic electrolytes and their mixtures at temperatures ranging up to $373.15 \mathrm{~K}$. That work includes studies of the enthalpies of mixing of reciprocal electrolyte pairs to test the reliability of T. F. Young's cross-square rule for mixing at both constant total ionic strength and at constant equivalent molality. Three of these papers [1-3] provided important information for the $\mathrm{NaCl}+\mathrm{Na}_{2}$ $\mathrm{SO}_{4}+\mathrm{H}_{2} \mathrm{O}$ system that helped my colleagues and me to construct a temperaturedependent thermodynamic model for this system [4]. Bob Wood kindly provided us with copies of theses and computer printouts documenting these experimental results in detail.

It should be noted that this is the second special issue devoted to papers presented at a symposium held at a Calorimetry Conference. The first such issue was based on papers presented at the 64th Calorimetry Conference held in Santa Fe, New Mexico from June 28 to July 2, 2009, published as issue 12 of volume 39 (2010) of our journal. The editors of this journal hope that there will be many more such special issues.

\section{References}

1. Wood, R.H., Smith, D.E., Chen, H.K.W., Thompson, P.T.: Heats of mixing aqueous electrolytes. XII. The reciprocal salt pair $\mathrm{Na}^{+}, \mathrm{Li}^{+} \| \mathrm{Cl}^{-}, \mathrm{SO}_{4}{ }^{2-}$. J. Phys. Chem. 79, 1532-1535 (1975)

2. Srna, R.F., Wood, R.H.: Heats of mixing aqueous electrolytes. XIII. The reciprocal salt pair $\mathrm{Na}^{+}$, $\mathrm{Mg}^{2+} \|_{\mathrm{Cl}^{-}}, \mathrm{SO}_{4}{ }^{2-}$. J. Phys. Chem. 79, 1535-1540 (1975)

3. Wood, R.H., Mayrath, J.E.: Enthalpies of mixing of some aqueous electrolytes at 373.15 K. J. Chem. Thermodyn. 14, 1135-1141 (1982)

4. Rard, J.A., Clegg, S.L., Platford, R.F.: Thermodynamics of $\left\{z \mathrm{NaCl}+(1-z) \mathrm{Na}_{2} \mathrm{SO}_{4}\right\}$ (aq) from $T=278.15 \mathrm{~K}$ to $T=313.15 \mathrm{~K}$, and representation with an extended ion-interaction (Pitzer) model. J. Chem. Thermodyn. 35, 967-1008 (2003) 